\title{
CARACTERIZAÇÃO BIOCLIMÁTICA DE UM GALPÃO EXPERIMENTAL DE CRIAÇ̃̃O DE FRANGOS DE CORTE NA REGIÃO DE DIAMANTINA-MG
}

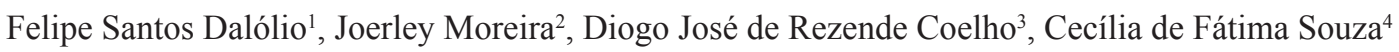

\section{RESUMO}

Objetivou-se com este trabalho avaliar as condições bioclimáticas de um galpão experimental de frangos de corte da Universidade Federal dos Vales do Jequitinhonha e Mucuri (UFVJM), no campus JK, em Diamantina, MG. A avaliação foi feita com base na mensuração das variáveis ambientais de temperatura do ar, umidade relativa do ar, temperatura de globo negro e velocidade do ar no interior da instalação, em 42 dias de período experimental. Com os dados coletados foram calculados os índices de temperatura e umidade (ITU), o índice de temperatura de globo negro e umidade (ITGU), a carga térmica de radiação (CTR) e o índice de entalpia $\left(\mathrm{H}^{\circ}\right)$. O desempenho foi avaliado aos 42 dias de idade dos frangos, através dos parâmetros de peso vivo (PV), ganho de peso médio diário (GPMD), consumo de ração (CR), conversão alimentar (CA) e viabilidade criatória (VB). Verificou-se que, na maior parte do período experimental, a temperatura no interior do galpão esteve fora da zona de conforto térmico para as aves e a umidade relativa do ar encontrou-se acima dos limites recomendados, exceto no horário de 15:00 horas. O ITU esteve abaixo da zona de conforto até a segunda semana, indicando que as aves estiveram em estresse por frio neste período. O ITGU às 21:00 horas esteve fora do preconizado durante todo o período experimental. A CTR e o $\mathrm{H}^{\mathrm{o}}$ também estiveram abaixo do preconizado em todo o período experimental, indicando pouca quantidade de calor na instalação onde os animais foram alojados. O desempenho dos frangos de corte mostrou-se inferior ao esperado. Neste sentido, recomenda-se realizar alterações no galpão como: reduzir as entradas de ar, diminuir o volume de ar a ser aquecido nas primeiras semanas de vida das aves e fornecer aquecimento suplementar ao nível de galpão, afim de, proporcionar o melhor conforto térmico e, consequentemente, maior desempenho produtivo dos frangos.

Palavras-chave: avicultura, bem-estar, conforto térmico, desempenho, índices.

\section{ABSTRACT \\ BIOCLIMATIC CHARACTERIZATION OF AN EXPERIMENTAL SHED BROILER CREATION IN THE REGION OF DIAMANTINA-MG}

The objective of this study was to evaluate the bioclimatic conditions of an experimental shed broiler Federal University of Vales do Jequitinhonha and Mucuri (UFVJM) in JK campus in Diamantina, MG. The assessment was made based on the measurement of environmental variables of air temperature, relative humidity, black globe temperature and air velocity within the facility, in 42-day trial. With the collected data we calculated the temperature and humidity index (THI), the black globe temperature and humidity index (BGTHI), the radiation heat load (RHL) and the enthalpy index $\left(\mathrm{H}^{\circ}\right)$. The performance was evaluated at 42 days of age the broiler chickens through the parameters live weight (LW), average daily gain weight (ADGW), feed intake (FI), feed conversion ratio (FCR) and production viability (PV). It was found that most of the trial period the temperature inside the shed was out of thermal comfort zone for birds and the relative humidity was found above the recommended limits, except in the 15:00. The THI was below the comfort zone until the second week, indicating that the birds were in cold stress in this period. The BGTHI at 21:00 was outside the recommended throughout the experimental period. RHL and the $\mathrm{H}^{\circ}$ also were below the recommended throughout the trial period, indicating little amount of heat in the facility where the animals were housed. The performance of the broiler chickens proved to be lower than expected. In this sense, it is recommended to make changes in the shed to: reduce air intake, decrease the volume of air to be heated in the first weeks of bird life and provide additional heating to the shed level in order to, provide the best thermal comfort and hence higher performance of broilers.

Keywords: poultry, welfare, thermal comfort, performance, indexes.

Recebido para publicação em 17/11/2015. Aprovado em 09/03/2016.

1 - Zootecnista, Doutorando, Universidade Federal de Viçosa, UFV - felipesantos181@hotmail.com

2 - Zootecnista, Professor da Universidade Federal dos Vales do Jequitinhonha e Mucuri, UFVJM. joerleym@gmail.com

3 - Eng ${ }^{\circ}$ Agrícola, Doutorando, Universidade Federal de Viçosa, UFV - diogo.coelho@ufv.br

4 - Enga Agrícola, Professora da Universidade Federal de Viçosa, UFV - cfsouza@ufv.br 


\section{INTRODUÇÃO}

A avicultura de corte é um dos segmentos de maior destaque no agronegócio brasileiro, e representou, em 2014, cerca de, 1,5\% do PIB brasileiro (ABPA, 2015). Esse setor avançou de forma significativa após a integralização da cadeia produtiva, na década de 80 e, principalmente, devido a maior adoção de tecnologia. Dentre os mecanismos de incremento tecnológico pode se destacar os avanços no melhoramento genético, na nutrição, no manejo, na ambiência e na sanidade das aves, o que resultou em frangos cada vez mais eficientes no aproveitamento dos nutrientes.

No entanto, os animais tornaram-se mais sensíveis às variáveis ambientais estressantes devido ao fato dessas comprometerem a manutenção da sua homeotermia (TINÔCO, 2001). As condições térmicas representadas pela temperatura, umidade relativa e movimentação do ar, são as que mais afetam os animais, pois influenciam os mecanismos de troca de calor, sensível e latente, com o meio (BAÊTA; SOUZA, 2010).

Para que as aves tenham mínima fração de energia utilizada para manter sua temperatura corporal e máxima utilização para produção, é necessário que permaneçam em conforto térmico (DALÓLIO et al., 2015). A temperatura ambiente indicada para frangos de corte, na fase adulta, varia entre 18 e $22{ }^{\circ} \mathrm{C}$ dependendo da umidade relativa do ar (50 a $70 \%)$ considerando que a temperatura interna das aves oscila entre 40-41,5 ${ }^{\circ} \mathrm{C}$ (BAÊTA; SOUZA, 2010; FERREIRA, 2011). Quando as condições ambientais no interior da instalação não estão dentro dos limites adequados, o ambiente térmico torna-se desconfortável. Além disso, a criação de maneira intensiva faz com que as aves tenham reduzida margem para ajustes comportamentais necessários (MACARI et al., 2004). Dessa forma, o progresso nos índices de produtividade depende das condições do ambiente físico no qual a ave está inserida.

As condições do ambiente físico são função de diversas variáveis e podem seravaliadas pelos índices de conforto e de desconforto térmico (AMARAL et al., 2011). Os parâmetros de conforto devem englobar em um único valor, o efeito combinado da associação entre os elementos metereológicos e do ambiente construído (OLIVEIRA et al., 2006). Neste sentido, alguns índices como o ITU, o ITGU e o $\mathrm{H}^{\mathrm{o}}$, mensurados a partir dos valores de temperatura do ar e de umidade relativa, vêm sendo empregados para avaliar as características bioclimáticas das instalações para aves, afim de identificar sua efetividade na manutenção do conforto térmico (MEDEIROS et al., 2005; MENEGALI et al., 2009; ROCHA et al., 2010).

Assim sendo, a produtividade satisfatória dos frangos depende das condições térmicas do ambiente de alojamento, que refletem a combinação dos efeitos da temperatura de bulbo seco, da umidade relativa, da radiação solar incidente e da velocidade do ar a que a ave está submetida (GARCIA et al., 2012). Portanto, o sucesso da produção avícola depende, entre outros fatores, da redução dos efeitos climáticos indesejáveis sobre os animais, sendo necessário, portanto, a caracterização do ambiente térmico.

Neste contexto, objetivou-se realizar a caracterização bioclimática de um galpão experimental de frangos de corte, no setor de avicultura da UFVJM, localizado no campus JK, na cidade de Diamantina-MG.

\section{MATERIAL E MÉTODOS}

O presente trabalho foi realizado em um galpão experimental de frangos de corte da Universidade Federal dos Vales do Jequitinhonha e Mucuri (UFVJM), localizado na cidade de Diamantina-MG, na altitude de 1387 metros, $18^{\circ} 10^{\prime} \mathrm{S}$ de latitude e $43^{\circ} 30^{\prime} \mathrm{W}$ de longitude, na mesorregião do Alto Vale do Jequitinhonha, no período de 10 de maio a 20 de junho, durante o outono. O clima da região, segundo a classificação Köppen, é Cwb, temperado úmido, com inverno seco e chuvas no verão.

O galpão experimental possui dimensões de 8 $\mathrm{m}$ de largura e $40 \mathrm{~m}$ de comprimento, com 3,5 $\mathrm{m}$ de pé direito e cobertura com telhas de fibrocimento. Possui ainda, muretas laterais de $0,60 \mathrm{~m}$ de altura, 
piso de concreto, tela de arame galvanizado para fechamento lateral, cortinas laterais na cor amarela e sem climatização artificial. O galpão foi construído na orientação leste-oeste e possui gramado como vegetação circundante além de cerca viva lateral de Sansão do Campo.

Para a caracterização das condições ambientais, foram realizadas três leituras diárias, nos horários das 9:00, 15:00 e 21:00 horas, durante os 42 dias do ciclo de criação dos frangos de corte. As leituras foram feitas em nove pontos distintos do galpão, com três repetições para cada variável, realizando as seguintes medições: temperatura de globo negro, temperatura ambiente, umidade relativa e velocidade do ar no interior da instalação. Para medição da umidade relativa e da temperatura do ar, foi utilizado um termômetro de globo portátil modelo ITWTG-2000, e para aferir a velocidade do vento foi utilizado um anemômetro Kestrel. Os aparelhos utilizados para mensuração das variáveis ambientais foram posicionados na direção dos animais a $0,40 \mathrm{~m}$ do solo, conforme metodologia proposta por Rocha et al. (2010).

A partir da coleta dos dados mencionados foi calculado o índice de temperatura e umidade (ITU), de acordo com Thom (1959), pela Equação 1.

$$
\mathrm{ITU}=0,72\left(\mathrm{~T}_{\mathrm{bs}}+\mathrm{T}_{\mathrm{bu}}\right)+40,6
$$

em que,

Tbs = temperatura de bulbo seco $\left({ }^{\circ} \mathrm{C}\right)$; e

$\mathrm{Tbu}=$ temperatura de bulbo úmido $\left({ }^{\circ} \mathrm{C}\right)$.

$\mathrm{O}$ índice de temperatura de globo negro e umidade (ITGU) foi determinado conforme proposto por Buffington et al.(1981) pela Equação 2.

$$
\mathrm{ITGU}=\operatorname{Tgn}+0,36 . \text { Tpo }-330,08
$$

em que,

Tgn $=$ temperatura de globo negro $(\mathrm{K})$; e

Tpo $=$ temperatura de ponto de orvalho $(\mathrm{K})$.
A carga térmica de radiação (CTR, em $\mathrm{W} \mathrm{m}^{-2}$ ) foi calculada de acordo com o proposto por Esmay (1969), dado pela Equação 3.

$\mathrm{CTR}=\sigma(\mathrm{TRM})^{4}$

em que,

$\sigma=$ constante de Stefan-Boltzman $\left(5,67.10^{-8} \mathrm{~W} \mathrm{~m}^{-2}\right.$ $\left.\mathrm{K}^{-4}\right)$.

A temperatura radiante média (TRM), foi calculada por meio da Equação 4.

$\mathrm{TRM}=100 \cdot\left[2,51 \cdot \mathrm{v}^{1 / 2} \cdot(\mathrm{Tgn}-\mathrm{Ta})+(\mathrm{Tgn} / 100)^{4}\right]^{1 / 4}$

em que,

$\mathrm{v}=$ velocidade do vento em $\mathrm{m} \cdot \mathrm{s}^{-1}$;

Tgn = temperatura de globo negro $(\mathrm{K})$; e

$\mathrm{Ta}=$ temperatura ambiente $(\mathrm{K})$.

O índice de entalpia foi calculado de acordo com Barbosa Filho et al. (2007), por meio da Equação 5.

$\mathrm{H}^{\circ}=6,7+0,243 \cdot \mathrm{T}_{\mathrm{bs}+}\left[(\mathrm{UR} / 100) \cdot 10^{(7,5 \cdot \mathrm{Tbs}) /(237,3+\mathrm{Tbs})}\right](5)$

em que,

$\mathrm{H}^{\circ}=$ entalpia $(\mathrm{kcal} / \mathrm{kg}$ ar seco);

Tbs = temperatura do bulbo seco $\left({ }^{\circ} \mathrm{C}\right)$; e

$\mathrm{UR}=$ umidade relativa do ar $(\%)$.

No galpão experimental foram alojados 720 pintinhos, fêmeas, da linhagem Cobb 500, com peso médio inicial de 55,0 $\pm 5,0 \mathrm{~g}$, distribuídos em 36 boxes de $4 \mathrm{~m}^{2}$, com 25 aves por unidade experimental. No período total de criação, 1 a 42 dias, foi fornecido para as aves ração basal a base de milho e de farelo de soja segundo recomendação de Rostagno et al. (2011). Aos 42 dias de idade, as aves e as sobras de ração total fornecida, foram pesadas para mensuração das variáveis de desempenho: PV (peso vivo), 
CR (consumo de ração), GPMD (ganho de peso médio diário) e CA (conversão alimentar). A mortalidade foi registrada diariamente, para posterior apresentação dos dados de viabilidade criatória (VB).

Posteriormente à coleta dos dados brutos correspondentes às variáveis ambientais e dos dados de desempenho produtivo dos frangos, foi retirado à média de cada parâmetro para confecção das figuras ilustrativas e do quadro experimental. Os dados ambientais e seus respectivos índices foram comparados com as referências na literatura em relação ao tema proposto e à fase de criação das aves. Os dados produtivos dos frangos de corte, por sua vez, foram comparados àqueles preconizados no Manual da linhagem Cobb 500 (2013) em estudo. A comparação entre os dados experimentais e àqueles oriundos da literatura, não se deu de maneira estatística e sim através da análise do comportamento e de maneira ilustrativa no intuito de demonstrar a importância do fornecimento de ambiente térmico adequado às aves de produção.

\section{RESULTADOS E DISCUSSÃO}

O comportamento dos dados médios de temperatura ambiente $\left({ }^{\circ} \mathrm{C}\right)$ e de umidade relativa do ar (\%) no ambiente interno do galpão durante todo o ciclo produtivo está apresentado na Figura 1 (a) e 1 (b), respectivamente.

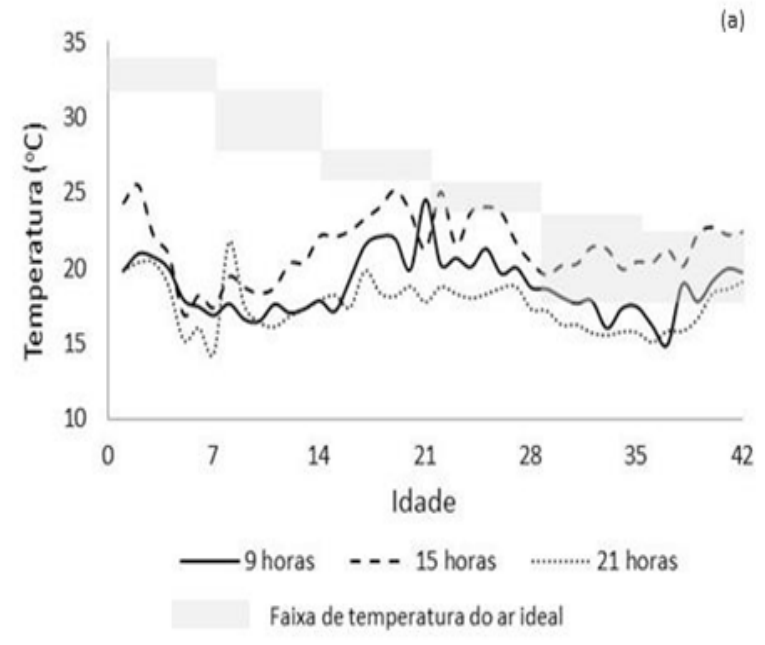

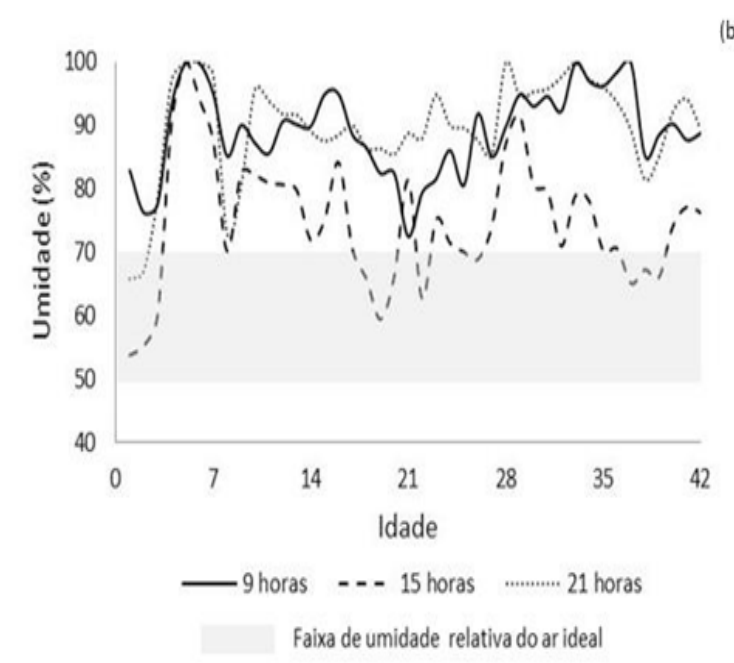

Figura 1(a) e 1(b). Valores médios de temperatura ambiente $\left({ }^{\circ} \mathrm{C}\right)$ e de umidade relativa do ar (\%), no período de 1 a 42 dias de vida das aves, em diferentes horários, com faixa de temperatura e de umidade relativa do ar ideais de acordo com Ávila (2004) e Baêta e Souza, (2010), respectivamente.

Pode-se observar, na Figura 1(a), que a temperatura do ar no galpão, até a quarta semana de criação das aves, esteve fora da zona de conforto térmico, em todos os horários. A partir da quarta semana de criação somente os dados coletados às 15:00 horas estiveram dentro da zona de conforto térmico. Assim, as aves permaneceram em estresse por frio durante a maior parte do período experimental. Fato este que pode estar associado à época de coleta dos dados, durante a transição do outono para o inverno, e a inadequação da instalação para a manutenção do conforto térmico. Vale ressaltar as características intrínsecas do microclima da região, na qual a instalação está inserida, classificada como temperado úmido, além da elevada altitude associada às oscilações bruscas de temperatura ao longo do dia (GIANOTTI et al., 2013).

Verifica-se, por meio da Figura 1(b) que, em todas as semanas, os valores de umidade relativa interna do galpão estiveram fora da faixa ideal (50 - $70 \%$ ), preconizada por Baêta \& Souza (2010). E que, somente em alguns dias os valores 
observados às 15:00 horas estiveram dentro da faixa ideal. Os dados referentes à UR, ao longo de todo o período experimental, tiveram seus menores valores médios às 15:00 horas. Comportamento semelhante também foi verificado por Moraes et al. (1999), Zanolla et al. (1999) e Furtado et al. (2006). Vieira et al. (2010), caracterizando o microclima do município de Diamantina, afirmaram que aumentos de umidade relativa e de pressão de vapor ocorrem com grande facilidade independente da época e da estação do ano. Tal fato indica algumas particularidades da microrregião do Espinhaço Meridional e, em partes, explica os valores elevados de umidade relativa no interior do galpão, ao longo de todo o período experimental.

Na Figura 2 e na Figura 3 estão representadas as variações do índice de temperatura e umidade (ITU) e do índice de temperatura de globo negro e umidade (ITGU), respectivamente, durante todo o período experimental, em diferentes horários.

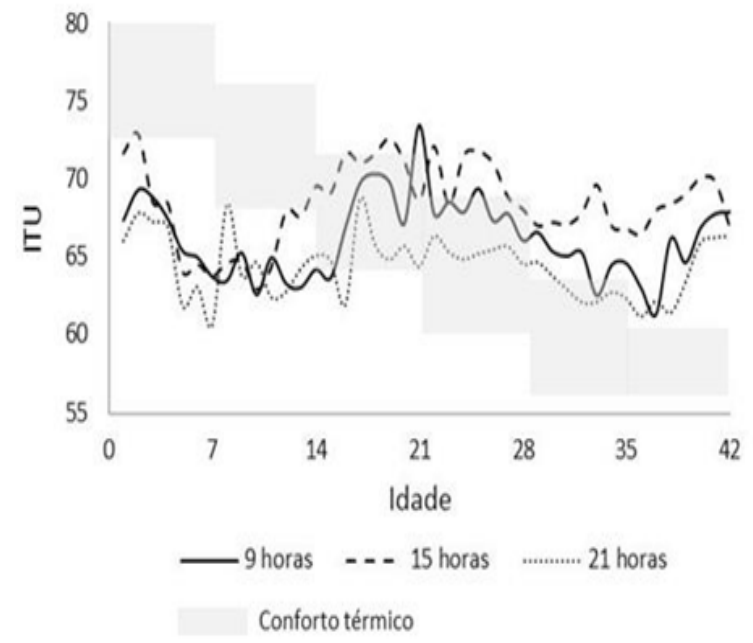

Figura 2. Valores médios do índice de temperatura e umidade (ITU) no período de 1 a 42 dias de vida das aves, em diferentes horários, e representação das faixas ideais de conforto de acordo com Teixeira (1983) e Abreu \& Abreu (2001).

Observa-se na Figura 2 que o índice de temperatura e umidade (ITU), às 9:00 e 21:00 horas, encontra-se dentro dos limites recomendados por Abreu \& Abreu (2001), para aves com 14 a 28 dias de idade. No entanto, a partir da terceira semana os valores de ITU são superiores aos ideais.

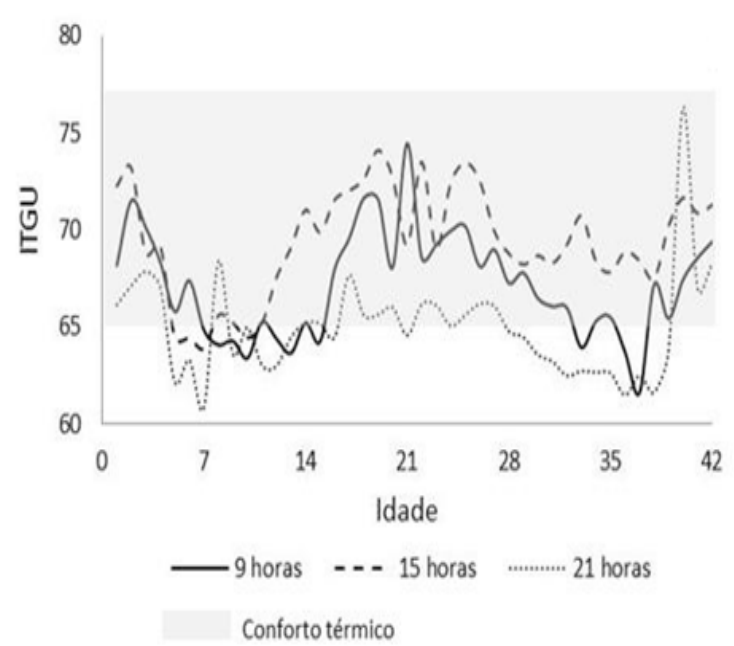

Figura 3. Valores médios do índice de temperatura de globo negro e umidade (ITGU), no período de 1 a 42 dias de vida das aves, em diferentes horários, e representação das faixas ideais de conforto de acordo com Medeiros et al. (2005).

Tendo em vista que o ITU não considera a carga térmica radiante como parâmetro, preconiza-se a utilização em conjunto com o ITGU para avaliar a ambiência nas instalações rurais para criação de animais. Afinal, o ITGU engloba, em um único valor, os efeitos da temperatura de bulbo seco, da temperatura de bulbo úmido, da radiação, bem como da movimentação do ar (FERREIRA, 2011). Ambientes e instalações cujos valores de ITGU variam entre 65 e 77, não afetam o desempenho dos frangos de corte (TEIXEIRA, 1983). Ainda, Medeiros et al. (2005) afirmam que quando os valores de ITGU encontram-se entre 69 e 77 os frangos permanecem calmos e dispersos, com consequente acréscimo nos índices de produtividade. Dessa maneira, verifica-se que na segunda semana, no horário de 21:00 horas, os valores encontrados estão fora do recomendado e somente na terceira semana o ITGU encontra-se na faixa ideal em todos os horários analisados.

Os valores de ITGU foram mais elevados às 15:00 horas, devido à elevação da temperatura da vizinhança do globo negro principalmente, da temperatura do solo aquecido e da superfície inferior da cobertura. Esta tendência também foi verificada por Zanolla et al. (1999), Moraes et al. (1999) e Furtado et al. (2003). 
Na Figura 4 e na Figura 5, estão representadas as variações dos índices de carga térmica radiante $(\mathrm{CTR})$ e de entalpia $\left(\mathrm{H}^{\circ}\right)$, respectivamente, durante todo o período de criação das aves.

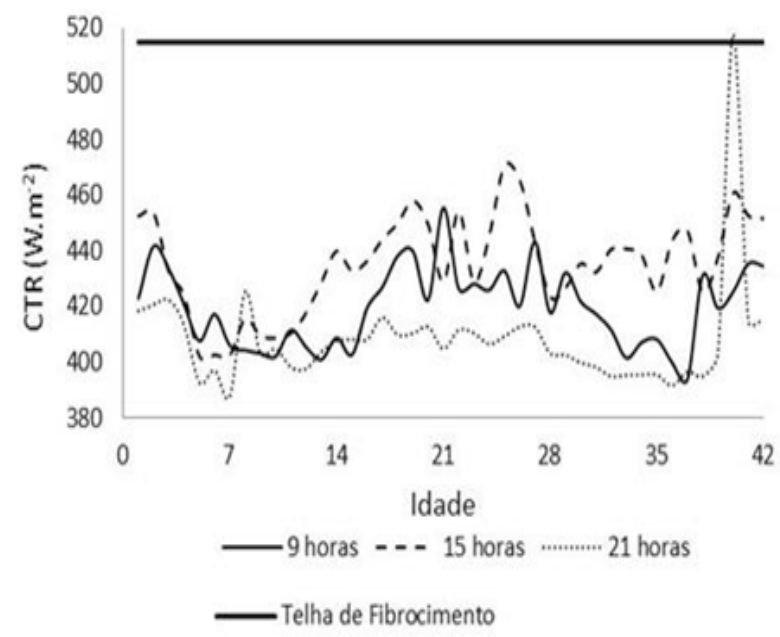

Figura 4. Valores médios de carga térmica radiante (CTR), no período de 1 a 42 dias de vida das aves, em diferentes horários, e representação da faixa de referência da CTR, para telhado de fibrocimento, segundo Rosa (1984).

A carga térmica radiante (CTR) é um importante componente indicador de conforto térmico e expressa a radiação total recebida por um globo negro a partir do ambiente circundante (CURTIS, 1983). Rosa (1984) considera 515,0 W. $\mathrm{m}^{-2}$ como valor de referência ideal de CTR, para instalações com telhado de fibrocimento. Os valores correspondentes à CTR encontrados neste estudo foram inferiores em todos os dias de coleta, em consequência dos valores de temperatura de globo negro (Tgn) e de temperatura de bulbo seco (Tbs), que se apresentaram baixos ao longo de todo o período experimental. Os menores e os maiores valores de CTR ocorreram às 21:00 e às 15:00 horas, respectivamente.

A CTR sofre alterações, principalmente, em função da irradiação solar direta, a qual atinge os valores mais elevados próximos do horário de 15:00 horas, quando o sol posiciona-se de forma mais perpendicular ao plano do horizonte local, e, também, em função da radiação de ondas longas emitidas pela vizinhança (ABREU et al., 2007; FIORELLI et al., 2010 e ALMEIDA; PASSINI, 2013). Além disso, a temperatura radiante média
(TRM), utilizada para o cálculo da CTR, em conjunto com o tipo de material utilizado como cobertura, causa influência direta nos valores de CTR. Portanto, de acordo com a época do ano e com a característica isolante de cada material de cobertura, é possível observar valores distintos de CTR, em uma mesma região.

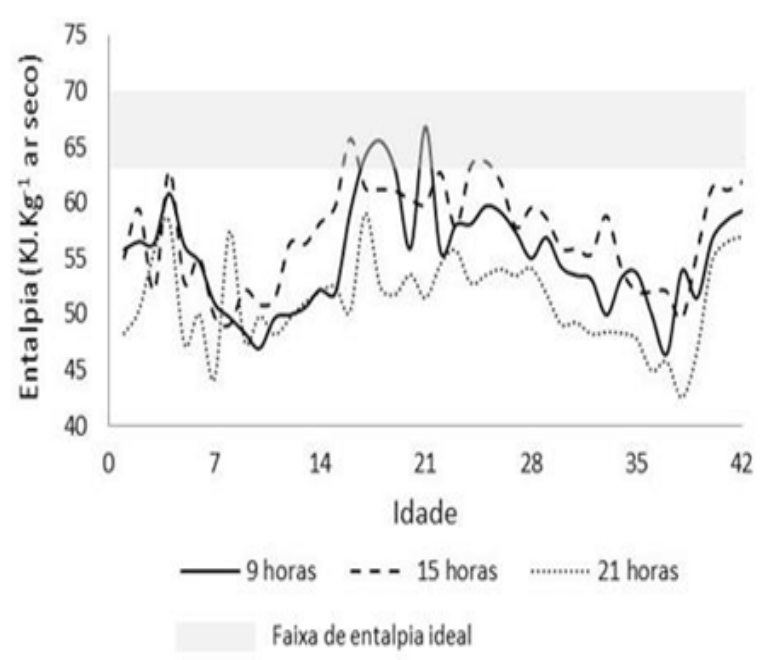

Figura 5. Valores médios de entalpia $\left(\mathrm{H}^{\circ}\right)$, no período de 1 a 42 dias de vida das aves, em diferentes horários, e representação da faixa de entalpia ideal para conforto das aves segundo Barbosa Filho (2007).

Com relação ao índice de entalpia, verifica-se que os valores encontrados estão abaixo do limite inferior preconizado por Barbosa Filho et al. (2007) (64-70 kJ/kg de ar seco), e isto representa uma condição crítica para as aves. Logo, pode-se inferir que a condição do ambiente interno do galpão está fora da condição de conforto para frangos de corte ao longo de todo o período experimental. O índice de entalpia indica a quantidade de calor presente no ambiente, sendo dado em função da temperatura ambiente e da umidade relativa do ar.

A partir da interpretação de todos os dados bioclimáticos analisados, ressalta-se a importância de realizar mudanças estruturais na instalação para que a mesma possa fornecer faixas adequadas de conforto térmico para as aves poderem expressar o seu máximo potencial produtivo e não prejudicar à condução de experimentos futuros, independentemente da época do ano em que o galpão será utilizado. 
Quadro 1. Valores médios de peso vivo (PV), ganho de peso médio diário (GPMD), consumo de ração (CR), conversão alimentar (CA) e viabilidade criatória (VB) de frangos de corte alojados no galpão experimental em comparação com oscitados no manual de criação da linhagem Cobb 500 (2013).

\begin{tabular}{lccccc}
\hline Parâmetros aos 42 dias & PV $(\mathrm{g})$ & GPMD $(\mathrm{g})$ & CR $(\mathrm{g})$ & CA $(\mathrm{g} / \mathrm{g})$ & VB $(\%)$ \\
\hline Desempenho experimental & 2419 & 57,60 & 4188 & 1,73 & 84,30 \\
Desempenho esperado & 2620 & 67,40 & 4573 & 1,70 & 96,00 \\
\hline
\end{tabular}

*Desempenho esperado: produtividade de fêmeas aos 42 dias de idade de acordo com o manual da linhagem Cobb 500 (2013).

No Quadro 1 estão apresentados os dados referentes aos parâmetros produtivos das aves. Pode-se observar que o desempenho esteve abaixo do esperado ao ser comparado com aves criadas em condição de conforto térmico, conforme recomendação do manual da linhagem Cobb 500 (2013).

Como resultado do desconforto ambiental temse a queda no desempenho zootécnico e o aumento de morbidade e de mortalidade em frangos de corte criados em condição de estresse por frio (LEESON et al., 1995). O estresse por frio favorece o surgimento de síndrome ascítica e de morte súbita, e essas doenças metabólicas ocorrem, em maior incidência, em regiões de maior altitude e sem aclimatação adequada (GONZÁLEZ et al., 2001), como observado no presente estudo. À medida que as aves distanciam-se das condições térmicas ideais, da zona termoneutra, apresentam taxas de mortalidade mais elevadas, queda no desempenho, na viabilidade criatória e, consequentemente, reduções no rendimento de carcaça e na qualidade final da carne.

Para manter a competitividade da produção avícola brasileira é imprescindível aperfeiçoar os abrigos e o manejo para superar os efeitos prejudiciais dos elementos ambientais críticos, como a temperatura e a umidade relativa do ar (NASCIMENTO et al., 2014). As instalações devem assegurar a manutenção da homeotermia para manter o conforto térmico animal e garantir o bem-estar na produção com o mínimo gasto de energia (SANTOS et al., 2009). Dessa forma, modificações nas instalações como redução das entradas de ar, instalação de cortina adicional, redução do volume de ar a ser aquecido nas primeiras semanas e fornecimento de aquecimento geral, tornam-se medidas necessárias e recomendadas para proporcionar conforto térmico às aves, com consequente ganho pela maior expressão do potencial produtivo.

\section{CONCLUSÕES}

- Por meio dos resultados obtidos e com base nas condições de realização do presente estudo, pode-se concluir que as aves não permaneceram em conforto térmico durante todo o período de criação. Por isso, medidas de melhoria no manejo e na adequação da instalação devem ser realizadas, para garantir melhor ambiente às aves, principalmente no período de outono e inverno;

- Apesar de ter sido fornecido fonte de aquecimento suplementar para as aves, nas três primeiras semanas de vida, o mesmo não foi suficiente para garantir índices térmicos satisfatórios ao longo de todo o galpão. Com isto recomenda-se fornecer aquecimento ao longo do galpão em conjunto com o aquecimento local, ao nível das aves.

\section{AGRADECIMENTOS}

Os autores agradecem a CAPES e ao $\mathrm{CNPq}$ pelo apoio financeiro.

\section{REFERÊNCIAS BIBLIOGRÁFICAS}

ABREU, V.M.N.; ABREU, P.G. Diagnóstico bioclimático para a produção de aves no Oeste paranaense. In: XXX CONGRESSO BRASILEIRO DE ENGENHARIA AGRÍCOLA, 30., 2001, Foz do Iguaçu. Anais... Foz do Iguaçu: CONBEA, [2001]. CD-ROM. 
ABREU, P.G.; ABREU, V.M.N.; COLDEBELLA, A.; JAENISCH, F.R.F.; PAIVA, D.P. Condições térmicas ambientais e desempenho de aves criadas em aviários com e sem o uso de forro. Arquivo Brasileiro de Medicina Veterinária e Zootecnia, Belo Horizonte, v.59, n.4, p. 1014-1020, 2007.

ALMEIDA, E.A.; PASSINI, R. Thermal comfort in reduced models of broilers houses, under different types of roofing materials. Engenharia Agrícola, Jaboticabal, v.33, n.1, p. 19-27, 2013.

AMARAL, A.G.; YANAGI JÚNIOR, T.; LIMA, R.R.; TEIXEIRA, V.H.; SCHIASSI, L. Efeito do ambiente de produção sobre frangos de corte sexados criados em galpão comercial. Arquivo Brasileiro de Medicina Veterinária e Zootecnia, Belo Horizonte, v.63, n.3, p. 649-658, 2011.

ÁVILA, V. S. Aspectos importantes a considerar na criação de frangos de corte no período frio. Versão eletrônica, Concórdia, 2004. Disponível em: <http://www.cnpsa.embrapa.br/?artigos/2004/ artigo-2004-015.htmal;ano=2004>. Acesso em: 08 fevereiro 2015.

ASSOCIAÇÃO BRASILEIRA DE PROTEÍNA ANIMAL (ABPA). Relatório Anual. 2015. Disponível em: $<$ http:// abpa-br.com.br/files/publicacoes/ c59411a243d6dab1da8e605be58348ac.pdf > . Acesso em: 17 de setembro de 2015.

BAÊTA, F.C.; SOUZA, C.F. Ambiência em edificações rurais: conforto animal. 2. Ed. Viçosa: Editora UFV, 2010. 269p.

BARBOSA FILHO, J.A.D.; VIEIRA, F.M.C.; GARCIA, D.B.; SILVA, M.A.N.; SILVA, I.J.O. Mudanças e uso das tabelas de entalpia. Piracicaba, 2007. Disponível em:<http://nupea. esalq.usp.br>. Acesso em: 19 de março 2015.

BUFFINGTON, D.E.; COLLASSO-AROCHO, A.; CANTON, G.H.; PITT, D. Black globehumidity index (BGHI) as comfort equation for dairy cows. Transaction of the ASAE, St. Joseph, v.24, n.3, p.711-714, 1981.
COBB. Desenvolvimento ótimo de frangos de corte. Guapiaçu, SP: Cobb Vantress, Brasil Ltda., 2013, 44p. Disponível em: <http://cobb-vantress. com/languages/guidefiles/055769bb-6a4b-41b7822e-44a32b85c629_pt.pdf $>$. Acesso em: 12 de setembro de 2014 .

CURTIS, S.E. Environmental management in animal agriculture. 2 Ed. Ames: Iowa State University Press, 1983. 407p.

DALÓLIO, F.S.; ALBINO, L.F.T.; LIMA, H.J.D.; SILVA, J.N.; MOREIRA, J. Heat stress and vitamin $\mathrm{E}$ in diets for broilers as a mitigating measure. Acta Scientiarum. Animal Sciences, Maringá, v.37, n.4, p.419-427, 2015.

ESMAY, M.L. Principles of animal environment. 2. Ed. Westport CT: ABI Publishing, 1969. 325p.

FERREIRA, R.A. Maior produção com melhor ambiente: para aves, suínos e bovinos 2ed. Viçosa: Editora Aprenda Fácil, 2011. 401p.

FIORELLI, J.; FONSECA, R.; MORCELI, J.A.B.; DIAS, A.A. Influência de diferentes materiais de cobertura no conforto térmico de instalações para frangos de corte no oeste paulista. Engenharia Agrícola, Jaboticabal, v.30, n.5, p.986-992, 2010.

FURTADO,D.A.;AZEVEDO,P.V.;TINÔCO,I.F.F. Análise do conforto térmico em galpões avícolas com diferentes sistemas de acondicionamento. Revista Brasileira de Engenharia Agrícola e Ambiental, Campina Grande, v.7, n.3, p.559-564, 2003.

FURTADO,D.A.;DANTAS,R.T.;NASCIMENTO, J.W.B.; SANTOS, J.T.; COSTA, F.G.P. Efeitos de diferentes sistemas de acondicionamento ambiente sobre o desempenho produtivo de frangos de corte. Revista Brasileira de Engenharia Agrícola e Ambiental, Campina Grande, v.10, n.2, p.484489, 2006.

GARCIA， R.G.; ALMEIDA PAZ, I.C.L; CALDARA, F.R.; NÄÄS, I.A.; PEREIRA, D.F.; FERREIRA, V.M.O.S. Selecting the most adequate 
bedding material for broiler production in Brazil. Revista Brasileira de Ciência Avícola, Campinas, v.14, n.2, p.71-158, 2012.

GIANOTTI, A.R.C.; SOUZA, M.J.H.; MACHADO, E.L.M.; PEREIRA, I.M.; VIEIRA, A.D.; MAGALHÃES, M.R.Análise microclimática em duas fitofisionomias do cerrado no alto vale do Jequitinhonha, Minas Gerais. Revista Brasileira de Meteorologia, São José dos Campos, v.28, n.3, p.246-256, 2013.

GONZÁLEZ, F.H.D.; HAIDA, K.S.; MAHLD, D.; GIANNESI, G.; KRONBAUER, E. Incidência de doenças metabólicas em frangos de corte no sul do Brasil e uso do perfil bioquímico sanguíneo para o seu estudo. Revista Brasileira de Ciência Avícola, Campinas, v.3, n.2, p.141-147, 2001.

LEESON S.; DIAZ G.J.; SUMMERS, J.D. Metabolic disorders and mycotoxins. Guelph: University Books, 1995. 352p.

MACARI, M.; FURLAN, R.L.; MAIORKA, A. Aspectos fisiológicos e de manejo para manutenção da homeostase térmica e controle de síndromes metabólicas. In: MENDES, A.A.; NAAS, I.A.; MACARI, M. (eds). Produção de frangos de corte. Campinas: Facta, 2004. p.137-156.

MEDEIROS, C.M.; BAÊTA, F.C.; OLIVEIRA, R.F.M.; TINÔCO, I.F.F.; ALBINO, L.F.T.; CECON, P.R. Índice térmico ambiental de produtividade para frangos de corte. Revista Brasileira de Engenharia Agrícola e Ambiental, Campina Grande, v.9, n.4, p.660-665, 2005.

MENEGALI, I.; TINÔCO, I.F.F.; BAÊTA, F.C.; CECON, P.R.; GUIMARÃES, M.C.C.; CORDEIRO, M.B. Ambiente térmico e concentração de gases em instalações para frangos de corte no período de aquecimento. Revista Brasileira de Engenharia Agrícola e Ambiental, Campina Grande, v.13, p.984-990, 2009.

MORAES, S.R.P.; TINÔCO, I.F.F.; BAÊTA, F.C.; CECON, P.R. Conforto térmico em galpões avícolas, sob coberturas de cimento amianto e suas diferentes associações. Revista Brasileira de Engenharia Agrícola e Ambiental, Campina Grande, v.3, n.1, p.89-92, 1999.

NASCIMENTO, G.R.; NÃ̃̃S, I.A.; BARACHO, M.S.; PEREIRA, D.F.; NEVES, D.P. Termografia infravermelho na estimativa de conforto térmico de frangos de corte. Revista Brasileira de Engenharia Agrícola e Ambiental, Campina Grande, v.18, n.6, p.658-663, 2014.

OLIVEIRA, R.F.M.; DONZELE, J.L.; ABREU, M.L.T.; FERREIRA, R.A.; VAZ, R.G.M.V.; CELLA, P.S. Efeitos da temperatura e da umidade relativa sobre o desempenho e o rendimento de cortes nobres de frangos de corte de 1 a 49 dias de idade. Revista Brasileira de Zootecnia, Viçosa, v.35, n.3, p.797-803, 2006.

ROCHA, H.P.; FURTADO, D.A.; NASCIMENTO, J.W.B.; SILVA, J.H.V. Índices bioclimáticos e produtivos em diferentes galpões avícolas no semiárido paraibano. Revista Brasileira de Engenharia Agrícola e Ambiental, Campina Grande, v.14, n.12, p.1330-1336, 2010.

ROSA, Y.B.C.J. Influência de três materiais de cobertura no índice de conforto térmico em condições de verão, para Viçosa - MG. 1984. 77p. Dissertação (Mestrado em Engenharia Agrícola) Universidade Federal de Viçosa, Viçosa, 1984.

ROSTAGNO, H.S; ALBINO, L.F.T.; DONZELE, J.L.; GOMES, P.C.; OLIVEIRA, R.F.M.; LOPES, D.C.; FERREIRA, A.S.; BARRETO, S.L.T.; EUCLIDES, R.F. Tabelas brasileiras para aves e suínos: composição dos alimentos e exigências nutricionais. 3ed. Viçosa: Editora UFV, 2011. $252 \mathrm{p}$.

SANTOS, P.A.; BAÊTA, F. C; TINÔCO, I.F.F.; ALBINO, L.F.T.; CECON, P.R. Ventilação em modos túnel e lateral em galpões avícolas e seus efeitos no conforto térmico, na qualidade do ar e no desempenho das aves. Revista Ceres, Viçosa, v.56, n. 2, p.172-180, 2009.

TEIXEIRA, V.H. Estudo dos índices de conforto 
em duas instalações de frango de corte para as regiões de Viçosa e Visconde do Rio Branco, MG. 1983. 59p. Dissertação (Mestrado em Engenharia Agrícola) - Universidade Federal de Viçosa, Viçosa, 1983.

THOM, E.C. The discomfort index. Weatherwise, Washington, v.12, n.2, p.57-60, 1959.

TINÔCO, I.F.F. Avicultura industrial: novos conceitos de materiais, concepções e técnicas construtivas disponíveis para galpões avícolas brasileiros. Revista Brasileira de Ciência Avícola, Campinas, v.3, n.1, p.1-26, 2001.
VIEIRA, J.P.G.; SOUZA, M.J.H.; TEIXEIRA, J.M.; CARVAVALHO, F.P. Estudo da precipitação mensal durante a estação chuvosa em Diamantina, Minas Gerais. Revista Brasileira de Engenharia Agrícola e Ambiental, Campina Grande, v.14, n.7, p.762-767, 2010 .

ZANOLLA, N.; TINÔCO, I.F.F.; BAÊTA, F.C.; CECON, P.R.; MORAES, S.R.P. Sistemas de ventilação em túnel e lateral na criação de frangos de corte em alta densidade. Revista Brasileira de Engenharia Agrícola e Ambiental, Campina Grande, v.3, n.3, p.361-366, 1999. 